\title{
Development of an Ontology for Modeling Spatial Planning Systems
}

\author{
Miltiades Lazoglou, Demos C. Angelides \\ Department of Civil Engineering, Aristotle University of Thessaloniki, Thessaloniki, Greece \\ Email: mlazoglou@civil.auth.gr
}

Received 22 May 2016; accepted 27 June 2016; published 30 June 2016

Copyright (C) 2016 by authors and Scientific Research Publishing Inc.

This work is licensed under the Creative Commons Attribution International License (CC BY). http://creativecommons.org/licenses/by/4.0/

(c) $\underset{\mathrm{EY}}{\mathrm{B}}$ Open Access

\begin{abstract}
The incorporation of computer-based technologies into spatial planning has increased the availability of spatial information. Ontologies are prominent in this process because they create repositories of digital information that can help an interdisciplinary interaction among experts, or between experts and citizens, or they can support informed decisions by policymakers or administration so as to limit discretionary powers and enhance shared community futures. This paper proposes an ontology that models the relations among the domestic actors, development policies, spatial schemes, spatial schemes' administrative bounds, spatial levels and evaluation process in a spatial planning system. Interests in this paper occur in gathering an enriched and complex knowledge base for planning purposes which can deal with the complexity of spatial problems in terms of knowledge, cognition, perception, domestic actors' behaviors and expectations, roles and interactions. The proposed ontology could be used as the core of a knowledge infrastructure for storing, organizing, and monitoring the implementations of existing spatial schemes and plans on national, regional, and local scales. As a case study, this paper discusses the spatial planning system in Greece, as such knowledge infrastructure is critically lacking in the Greek state.
\end{abstract}

\section{Keywords}

Spatial Planning Systems, Knowledge Management, Ontologies

\section{Introduction}

Computational tools enable the acquisition, organization, sharing, and reuse of knowledge and have therefore become broadly developed in spatial planning. Ontologies are central in this process because they can "develop a common understanding of the domain of interest and facilitate information exchange" (Kohli et al., 2012). They are also becoming increasingly recognized as essential tools in information science because they can 
bridge the gaps between planners and stakeholders through digital information repositories. Ontological approaches can deal with the complexity of spatial problems in terms of knowledge, cognition, perception, domestic actors' behaviours and expectations, roles and interactions.

This paper proposes an ontology that models the relations among the domestic actors, development policies, spatial schemes, spatial schemes' administrative bounds and spatial levels of the spatial planning system as well as the evaluation process, which follows the Strategic Evaluation Assessment (SEA) process, in a spatial planning system. Interests in this paper occur in gathering an enriched and complex knowledge base for planning purposes, as ontologies can help an interdisciplinary interaction among experts, or between experts and citizens, or they can support informed decisions by policymakers or administration so as to limit discretionary powers and enhance shared community futures.

As a case study, this paper discusses the spatial planning system in Greece as such knowledge infrastructure is critically lacking in the Greek state. The Greek spatial planning system follows the urbanism planning tradition (CEC, 1997) and presents a "strong architectural flavor and concern with urban design, townscape, and building control" (CEC, 1997). Its main feature is the "multiplicity of laws and regulations, predominance of a centralized, regulatory, and hierarchical planning style" (Nagy et al., 2012). The Greek spatial planning system includes in national- and regional-level strategic frameworks and in local-level regulatory plans.

The proposed ontology can be used as the core of a knowledge infrastructure for storing, organizing, retrieving and monitoring the implementations of existing schemes and plans at national, regional, and local scales.

\section{Background on Ontologies}

The exact meaning of the term "ontology" has been broadly discussed (Kohli et al., 2012; Agarwal, 2005; Klien et al., 2006; Arvor et al., 2013; Reynares et al., 2015; Visser et al., 2002). Researchers (Visser et al., 2002) briefly describe ontology as a "logical definition of concepts and their properties". Ontologies can facilitate communication among systems and people (Montenegro et al. 2012), by supporting reasoning and knowledge discovery. Both parameters are crucial in planning activities such as determining relationships, establishing rules, and accurately defining logical rationales (Katranuschkov et al., 2003).

Ontologies can be categorized as 1) top-level ontologies that integrate the ontologies of varying research fields and can guide the development of new ontologies (Hoehndorf, 2014); 2) domain ontologies, which conceptualize the tradeoffs and vocabularies of concepts within a specific domain; 3) task ontologies, which express the concepts and interactions of a certain task (Li et al., 2010), and 4) application ontologies that can meet circumscribed needs but cannot be extended to other applications or domains (Mejino Jr. et al., 2008).

Ontologies are based on standard representation languages (Arvor et al., 2013). The most popular representation language is the Resource Description Framework Schema (RDFS), a language which can hierarchically organize the features of ontologies (Arvor et al., 2013); and Ontology Web Language (OWL) 2.0 (W3C, 2012). OWL 2.0 was established by the World Wide Web Consortium (W3C) for three main purposes: 1) to ameliorate the limited expressivity of the RDF by incorporating novel advanced constructors (Arvor et al., 2013; McGuinness \& Van Harmelen, 2009), 2) to provide better machine interpretability than is possible with the RDF, and 3) to promote the development of the Semantic Web (Berners-Lee et al., 2001). The main features of an OWL 2.0 ontology are classes, properties, axioms, and individuals (Fenz, 2012). According to Buccela (Buccella et al., 2009) "classes represent entities or objects of the real world, properties are associated to a class or they represent relations between classes", axioms "represent additional constraints involving classes and/or properties” (Buccella et al., 2009), while individuals are instances of a specific class (Fenz, 2012).

\section{Ontologies and Spatial Planning}

The linkage of Semantic Web ontologies to spatial planning has been extensively reported in recent literature. Researchers (Bellini et al., 2014) designed a knowledge base for smart-city services that integrates heterogeneous data from multiple sources. Komninos et al. (2015) introduced an ontology based on the definitions of smart cities and identified the underlying causes of the low impact of smart energy and transport applications. Psyllidis et al. (2015) designed "SocialGlass", a web application that delineates the benefits and restrictions of linking social media to city datasets. Fox (2015) investigated means of facilitating the automated analysis of city indicators and related data on the Semantic Web. Montenegro et al. (2012) designed the LBCS, a tool-integrative ontology that delineates the relations established in urban spaces. Guyot et al. (2010) attempted to relate soft mo- 
bility to the CityGML model by coordinating and linking the rapidly growing urban ontologies.

Recently, ontologies have also been incorporated into urban management. The HarmonISA research project aims to monitor and integrate the regional land-use data of different countries semantically (HamonISA, 2015). The European COST C21 Action compiles 3D representations of support communications between "information systems, stakeholders, and urban experts at European levels” (Teller et al., 2010). Smart Objects for Intelligent Applications supports interpretability between heterogeneous devices and embedded systems (Otero-Cerdeira, et al., 2014). Semantic tools for carbon reduction in urban planning (SEMANCO) was designed for data storage and modeling in different places. SEMANCO aims to "create a multi-level energy model of an urban area" (SEMANCO, 2015). By implementing "awareness and interoperability for the adoption of ICT and semantic technologies in energy systems” (Garcia-Castro et al., 2014), the READY4 Smart Cities project attempts to minimize energy consumption and $\mathrm{CO}_{2}$ emissions.

\section{Proposed Ontology}

Our ontology was developed in OWL 2.0 using the Protégé 5.0 software (Noy et al., 2003). We also applied Geosparql (Perry \& Herring, 2012), a standard of the Open Geospatial Consortium that delineates "a vocabulary for representing geospatial data in RDF" (Beard, 2012) to facilitate the "representing and querying of geospatial data on the Semantic Web" (He et al., 2015). Its architecture comprises: 1) a core that specifies the classes of spatial objects, 2) a topology vocabulary for delineating the topological relations between spatial objects, 3) a geometry for modeling the geometry-based properties and nontopological functions of spatial objects, 4) a geometry topology that supports the query of topological functions, 5) an RDFS entailment that links RDF triples and RDFS semantics, and 6) a query rewrite component that examines the geometries and topological functions of spatial objects (Perry \& Herring, 2012).

To describe the relations established in the spatial planning system, the following classification was performed. The categories of the spatial schemes are designed under the ontology's "Spatial Scheme" class, the various kinds of development policies are designed under the ontology's "Development policy" class, the national, regional and local scales of a spatial planning system are designed under the ontology's "Spatial level" class, the domestic actors of a spatial planning system are designed under the ontology's "Actor" class, the spatial schemes' administrative bounds are designed under the ontology's "Geometry" class and the evaluation reports related to each spatial scheme belong to the "SEA process" class (Figure 1).

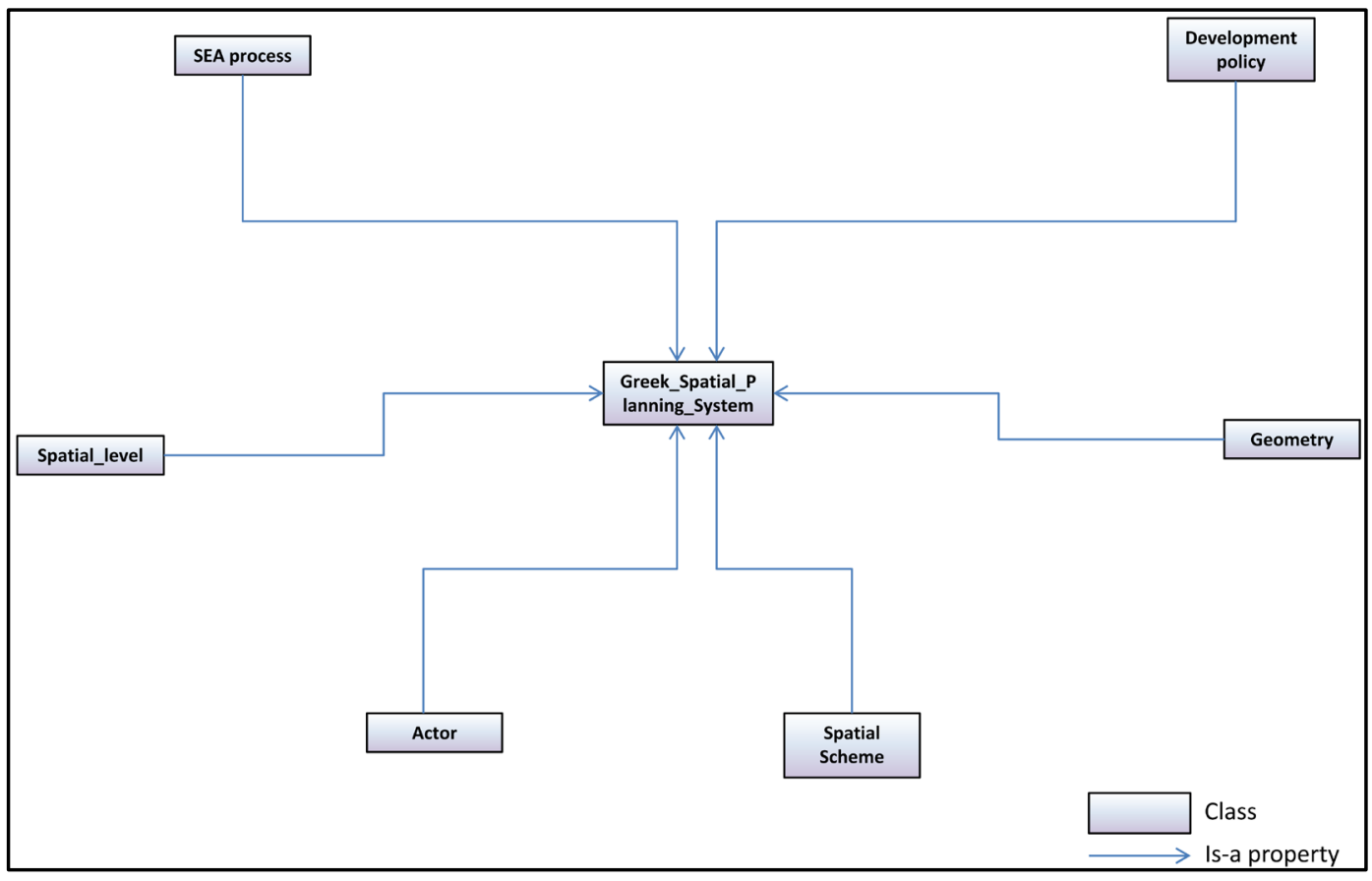

Figure 1. Classes and is-a properties of the proposed ontology. 
In order to express that a class is a subclass of another class is-a properties are designed while specific properties that relate individuals from one class to another (domain class and range class, respectively) are used, following the proposals of researchers (Jung et al., 2013).

Eight properties were designed to link the ontology's classes to the approval, elaboration, and review processes of each scheme. They are also related to the development policies applicable to each scheme, the spatial level to which the scheme is linked, the actors' official opinions of each scheme, the administrative bounds of each scheme and whether a particular scheme should follow the SEA process. For instance for the National Spatial Frameworks (NSF) the properties designed are 1) "NSF Approved by", 2) "NSF Elaborated by", 3) "NSF Follow the directions of", 4) "NSF Geometry", 5) "NSF Refer to", 6) "NSF Reviewed by", 7) "NSF Opinion Stated by", 8) "NSF Subject to" (see Figure 3). Similar properties were designed for each scheme.

As a case study, the provisions of Law 4269/2014, the core of the Greek spatial planning system, are discussed in this paper at all scales. An analysis of the relations established among the domestic actors, development policies, spatial schemes, spatial schemes' administrative bounds and spatial levels of the Greek spatial planning system as well as the evaluation process in the Greek spatial planning system is performed in local, regional and national scale during the next paragraphs, while the detailed structure of the Greek spatial planning system is also presented (see Figure 2). The existing schemes, schemes' administrative bounds, evaluation reports, development policies, SEA reports, along with the actors involved and the spatial level related can be represented as individuals under the respective classes and subclasses, creating in this way a valuable geo-database that facilitates the State, Municipalities and Regions to organize, control and monitor the evaluation of the established schemes in their territory. Planning and building in particular sectors such as industry and tourism are not considered, as they are subject to different legislative provisions. The ontology's properties and classes related to each spatial scheme on national, regional, and local scales are presented in Section 5.

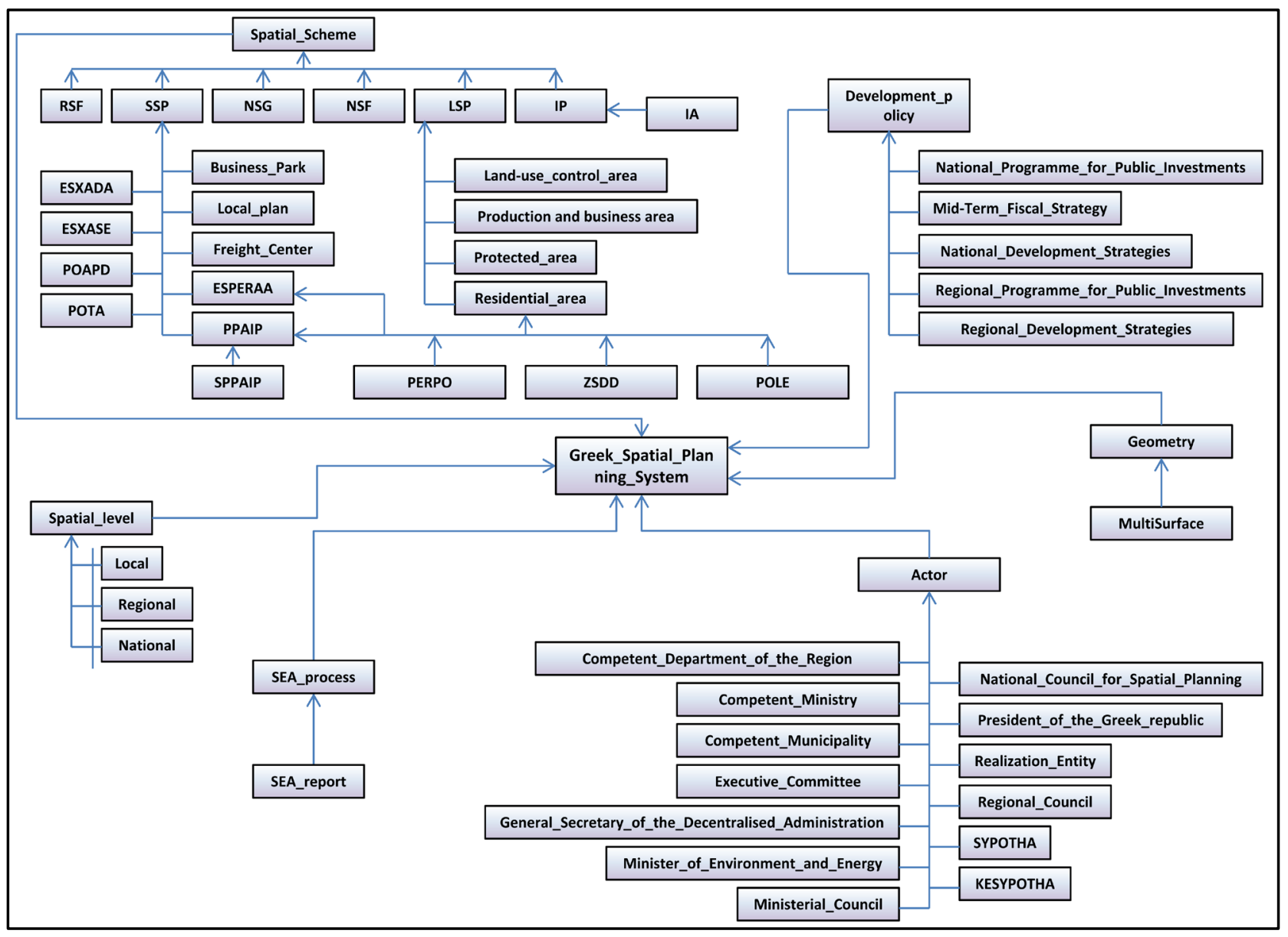

Figure 2. Classes, subclasses and properties of proposed ontology. 


\section{Domestic Actors, Schemes and Plans of the Greek Spatial Planning System}

\subsection{Characteristics of the Spatial Planning System in Greece}

The Greek spatial planning system is being steadily transformed because of the influence of the European Union (EU) policies; the broad availability of the EU development funds; administrative, economic, and social change; and the Kallikratis Programme (Law 3852/2014), which divides the Greek territory into seven decentralized administrations, thirteen regions, and three hunded twenty five municipalities. Properly implemented, these factors will impose a strategic, decentralized, and regionalized structure on the spatial planning system of Greece (Nagy et al., 2012). However, other factors such as bureaucracy (see Kyvelou, 2015) have hindered this process. Moreover, the existence of two pathologies-arbitrary construction and distinction between the within-plan and out-of-plan areas (see Kyvelou, 2015)—has widened the gap between the established plans and what is actually achieved (ESPON, 2015). To protect sensitive areas from urban sprawl and to comply with the Law 1337/1983 provisions, authorities have established Zones of Residential Control, which control unregulated building activities in many areas throughout the Greek territory.

The spatial planning law established in 1999 (Law 2742/1999) represented a shift toward strategic spatial planning and reflected the direct influence of EU planning policies on the Greek spatial planning system (Nagy et al., 2012; ESPON, 2015). The introduction of a new law (Law 4269/2014) in 2014 accelerated this trend by clearly distinguishing strategic and regulatory schemes, as discussed in Section 6.

\subsection{Domestic actors and Their Role in the Greek Spatial Planning System}

The role of domestic actors in shaping spatial planning priorities has been broadly highlighted (Dühr et al., 2010; Stead \& Cotella, 2011). Various actors are involved in the Greek spatial planning system and the relations among them are complicated or even vague. Their main duties and responsibilities are presented below.

The Greek Constitution previews the spatial planning frameworks and plans at all levels under the control of the State (Kyvelou, 2015). The Greek Parliament introduces the acts and laws of the frameworks, establishing the structure and procedures of spatial planning that should be followed at all scales. The President of the Republic is empowered to approve explicit plans, regulations, and measures by signing presidential decrees. The Council of State (i.e., the Supreme Administrative Court) creates judicial standards for interpreting the legislated priorities of sustainable development and spatial planning. Thus, the Council of State may be considered as the "producer of new norms and principles in the field of spatial planning" (Serraos et al., 2005).

In Greece, the Ministry of Environment and Energy coordinates most of the issues related to spatial planning at the national, regional, and urban scales. Other ministries (referred to as "competent ministries" in this paper), are responsible for specific sectors (i.e., industry, tourism, etc). The Ministerial Council is a decision-making body constituting the Government of Greece and is coordinated by the Prime Minister of Greece.

The National Council for Spatial Planning is the supreme consultation body on important issues regarding sustainable development and spatial planning policies throughout the Greek territory. Its main duties are to provide formal opinions on the National Spatial Strategy (NSG) and to prepare comments and suggestions on spatial planning issues of national importance when requested by the Minister of Environment and Energy. The council consists of 21 members representing various social groups (professional associations, environmental NGOs, academics, and public authorities). Another body is the Executive Committee, which submits opinions on NSFs and occasionally on Regional Spatial Frameworks (RSFs) when requested by the Minister of Environment and Energy.

Regions and municipalities have acquired central roles in spatial planning during the past few decades and are empowered with specific duties related to the elaborated schemes. Municipalities are administered by municipal councils, whose members are elected every five years, while particular issues are handled by various committees. The administrative body of a region is the Regional Council, whose members are elected every five years. It employs committees to elaborate on specific issues. To fulfill its objectives, each region is divided into departments that share specific responsibilities. Additionally, the seven decentralized administrations are administered by a general secretary appointed by the Ministry of Interior and Administrative Reconstruction.

The General Secretary of the Decentralized Administration establishes councils for urban affairs and disputes (SYPOTHAs). Each of these councils is based at the headquarters of its region and examines the appeals against the findings of building inspectors or omissions of building control institutions issued under the provisions of 
the arbitrary construction legislation. Each SYPOTHA is responsible for a region or a part of a region. Major issues may be referred to the Central Council for Urban Affairs and Disputes (KESYPOTHA), which is responsible for the entire Greek territory. The responsibilities of the above actors in spatial planning activities are detailed in the next section.

\subsection{National Level}

Law 4269/2014 provides two spatial planning instruments at the national level: the National Spatial Strategy and the National Spatial Frameworks.

\subsubsection{National Spatial Strategy}

Since 2014, the NSG has replaced the General Framework for Spatial Planning and Sustainable Development previewed in Law 2742/1999. The NSG is a set of principles that highlights the main directions and describes the mid-term and long-term spatial objectives of the Greek territory. Moreover, it proposes certain measures and actions to facilitate the implementation of the intended development. The NSG is elaborated under the responsibility and supervision of the Ministry of Environment and Energy and is approved by the Ministerial Council after consulting the National Council for Spatial Planning. Finally, the NSG is announced to Parliament. The NSF for the Greek territory was established in 2007.

\subsubsection{National Spatial Frameworks}

Since 2014, the NSFs have replaced the Special Frameworks for Spatial Planning and Sustainable Development previewed in Law 2742/1999. In text and diagrams, the NSFs outline the directions of strategic planning at the national level, focusing on 1) the spatial organization of the main national developmental axes, international and interregional input gates, and country connections; 2) the spatial structure of the national residential network; 3) the spatial structures of sectors critical to the national economy (i.e., industries); 4) the spatial structures of networks, services, and infrastructure and the spatial distribution of the knowledge and innovation infrastructure; 5) the spatial development and organization of areas with particular spatial, environmental, economic, or social significance, such as coastal zones, maritime areas, islands, mountainous, and less favored areas; and 6) the elaboration of plans, programs, and projects of major importance for spatial development.

The NSFs are elaborated by the Ministry of Environment and Energy and by competent ministries. The NSFs follow the directions and objectives of the NSG, the current National Programme for Public Investments, the National Development Strategies, and any other general or specific development policies of national programs. Where applicable, they also follow a mid-term fiscal strategy. The NSFs are approved by joint decisions of the Minister of Environment and Energy and other competent ministers while their content is assessed by the Executive Committee.

Conjointly with the competent ministries, the Ministry of Environment and Energy prepares at least one evaluation report every five years. This report details the necessary actions for effectively implementing the NSFs, identifies any problems in implementing the NSFs, and delineates the actions that oppose the proposed NSFs directions. The conclusions of this report are disclosed to the respective ministries and institutions for assessment. Furthermore, the Ministry of Environment and Energy and the competent ministers jointly appoint committees to monitor NSF implementation. The members of these committees are representatives of the above ministries. When stipulated by its evaluation report, an NSF may be reviewed five years after its establishment. In an urgent case, it can be modified earlier. Each NSF also includes an action plan that specifies the measures, actions, regulations, and programs for its implementation, as well as the actors and the timetable that should be followed. These relations are modeled in the proposed ontology (see Figure 3).

\subsection{Regional Level}

Law 4269/2014 provides one spatial planning instrument at the regional level, called Regional Spatial Framework (RSF).

\section{Regional Spatial Frameworks}

Since 2014, RSFs have replaced the Regional Frameworks for Spatial Planning and Sustainable Development previewed in Law 2742/1999. In texts and diagrams, the RSFs outline the directions of strategic spatial planning 


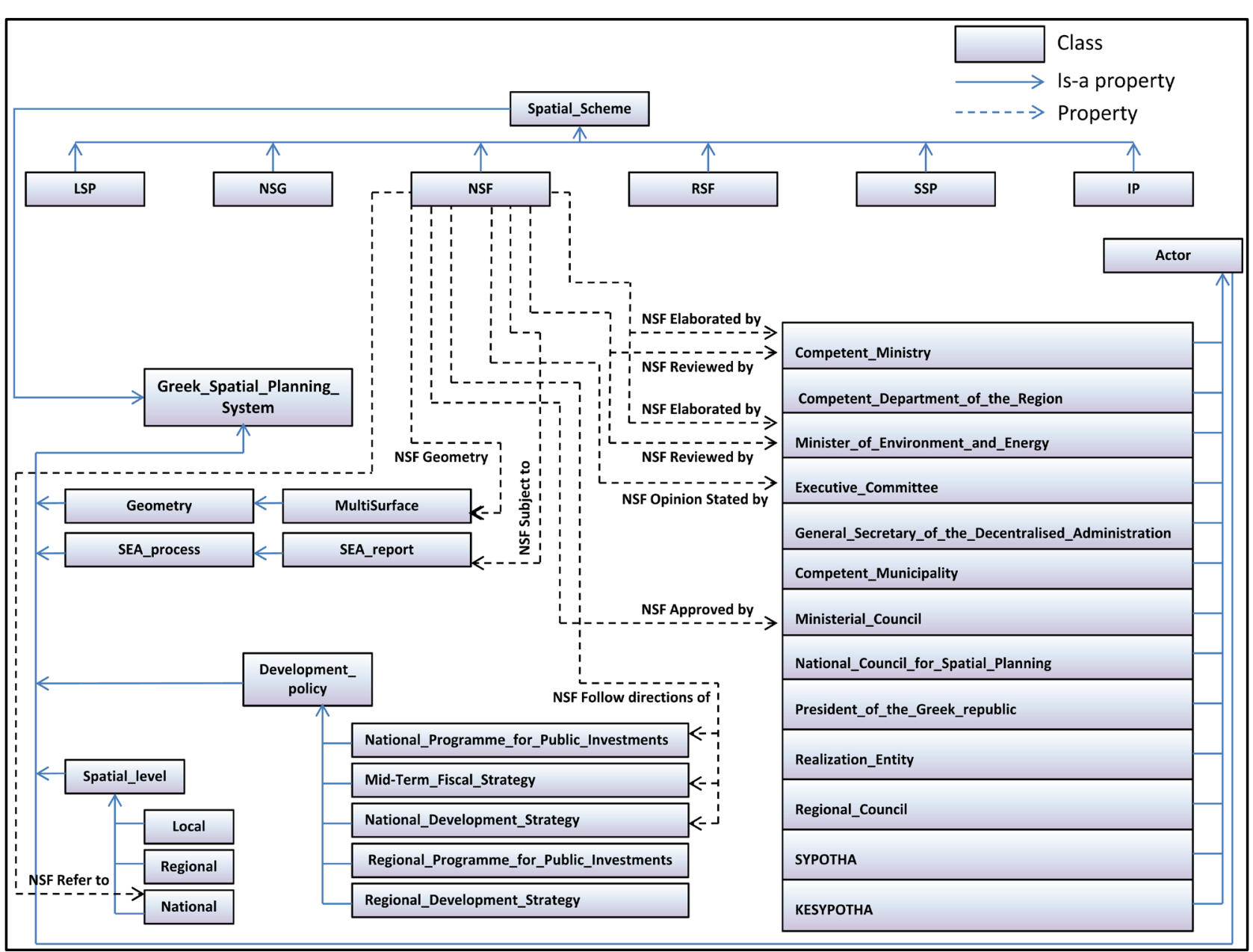

Figure 3. Classes and properties related to NSFs in proposed ontology.

at the regional level, focusing on 1) promoting and enhancing the specific attributes (such as primary agriculture and tourism) of each region; 2) the spatial structures of the production areas and sectors, which shape the region's development prospects; 3) the spatial structures of transport networks and technical infrastructure; 4) the spatial organization of the regional residential network, 5) initiatives related to regional- and urban-scale interventions and programs; 6) the management, promotion, and protection of cultural heritage and the ecological and architectural wealth of each region; and 7) the formulation of particular urban interventions. The RSFs must be consistent with the guidelines, priorities, and objectives of the NSG and NSFs but may elaborate on specific issues. Their priorities should follow the Regional Programme for Public Investments and the Regional Development Strategies.

Accompanied by text, charts, and maps, the RSFs include annexes that state the directions of each municipality. These directions relate to 1) existing areas suitable for special spatial measures previewed in Law 2742/1999, 2) organized spatial receptors related to public or private activities, 3) approved plans, and 4) any large-scale investments designed or existing within a competent region. Each RSF consists of an action plan specifying the measures, actions, regulations, and programs for its implementation, the actors, and the timetable that should be followed. The action plan may also include directions or feedback on the NSFs and NSG.

Every five years, the Ministry of Environment and Energy prepares at least one evaluation report that investigates the local applications, problems, and integration of policies. This report delineates the actions necessary for effectively implementing the RSFs and identifies measures that violate the RSFs directions. The report findings are then parsed by the Minister of Environment and Energy to relevant agencies and services for assessment. If deemed necessary by the evaluation report, an RSF can be reviewed five years after its establishment, or ear- 
lier in an urgent case. Evaluation reports can also be prepared by competent ministries. These ministries cooperate with the Ministry of Environment and Energy, which specifies the preparation, review, and amendment of the RSFs. These relations are modeled in the proposed ontology (see Figure 4). An RSF for each region was established in 2003-2004, and the RSFs are currently under review. In the Attica Region, the RSF is the Athens Regulatory (Master) Plan, whereas in the Region of Central Macedonia, the RSF must incorporate the provisions of the Regulatory (Master) Plan of Thessaloniki.

\subsection{Local Level}

Diachronically the spatial planning system in Greece has implemented numerous, substantive and detailed regulatory plans at the local scale since 1923 (Legislative Decree of July 17, 1923). Law 4269/2014 provides three local-scale spatial planning instruments: the Local Spatial Plans (LSPs), Special Spatial Plans (SSPs), and Implementation Plans (IPs).

\subsubsection{Local Spatial Plans}

Since 2014, LSPs have replaced General Urban Plans for both above or less than 2.000 inhabitants (named SCHOOAPs) that were previewed in Law 2742/1999. In text and diagrams, LSPs define the land uses, building provisions, and restrictions and state the measures necessary to integrate spatial development and to sustain the spatial organization of a municipality. LSPs follow the directions stated by the NSG, NSFs, and RSFs. LSPs are prepared by the Ministry of Environment and Energy or a Competent Municipality, subject to a public consultation process. The Ministry of Environment and Energy sets the required specifications and delineates other

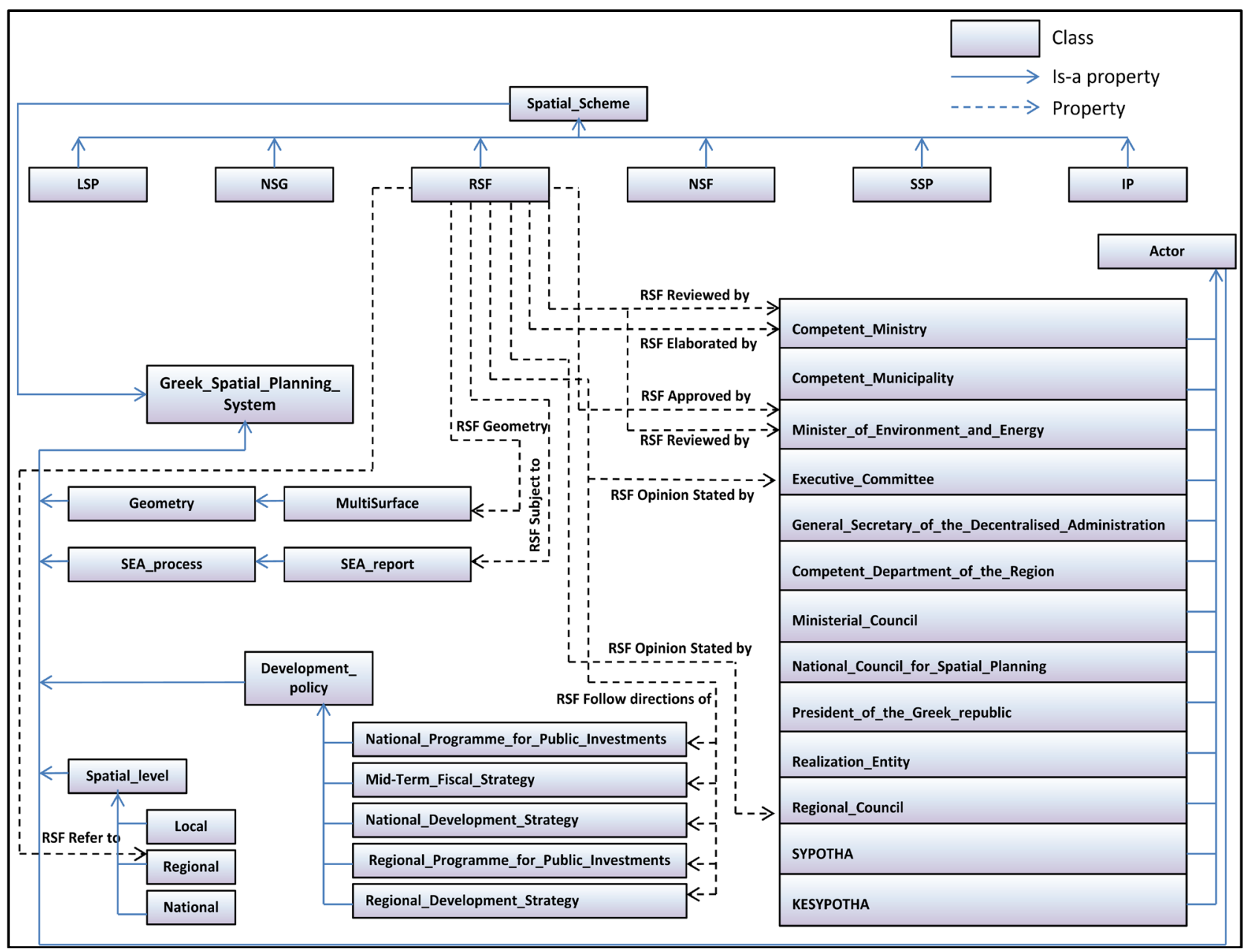

Figure 4. Classes and properties related to RSFs in proposed ontology. 
provisions required for the preparation, evaluation, and modification of each LSP. Every five years, the Decentralized Administration prepares at least one evaluation report examining the application and problems of LSPs and the extent to which the directions of the proposed LSPs are integrated at the underlying spatial levels. Moreover, the evaluation report delineates the actions necessary for effectively implementing the LSPs and identifies actions that violate the LSPs' directions. Evaluation reports can also be prepared by competent ministries in cooperation with the Ministry of Environment and Energy, which may recommend solutions to problematic issues. The conclusions of the evaluation report are parsed by the Minister of Environment and Energy to the respective municipality and region. If deemed necessary by the evaluation report, an LSP can be reviewed five years after its establishment. Earlier modification is possible if proposed by the Ministry of Environment and Energy and approved by the KESYPOTHA. Concurring with the opinions of local municipalities and competent SYPOTHAs, the Minister of Environment and Energy also proposes presidential decrees for LSP legislation. However, no official geographically referenced database currently exists for already established or under-review LSPs. These relations are modeled in the proposed ontology (see Figure 5).

Furthermore, LSPs designate the following categories to each municipality.

1) Residential areas

This category concerns the living, economic, and social activities of citizens. Residential areas can be designated within any already approved LSP, settlements established before 1923, settlements with fewer than 2000 residents, and areas appropriate for urbanization (i.e., areas with suitable location, geological, and other conditions for residential, urban, and program developments). The LSPs specify various parameters, such as the limits of the urbanization process, spatial organization, public services, public infrastructure and networks, restrictions on land uses and urban density, and building provisions. They also establish the following subcategories.

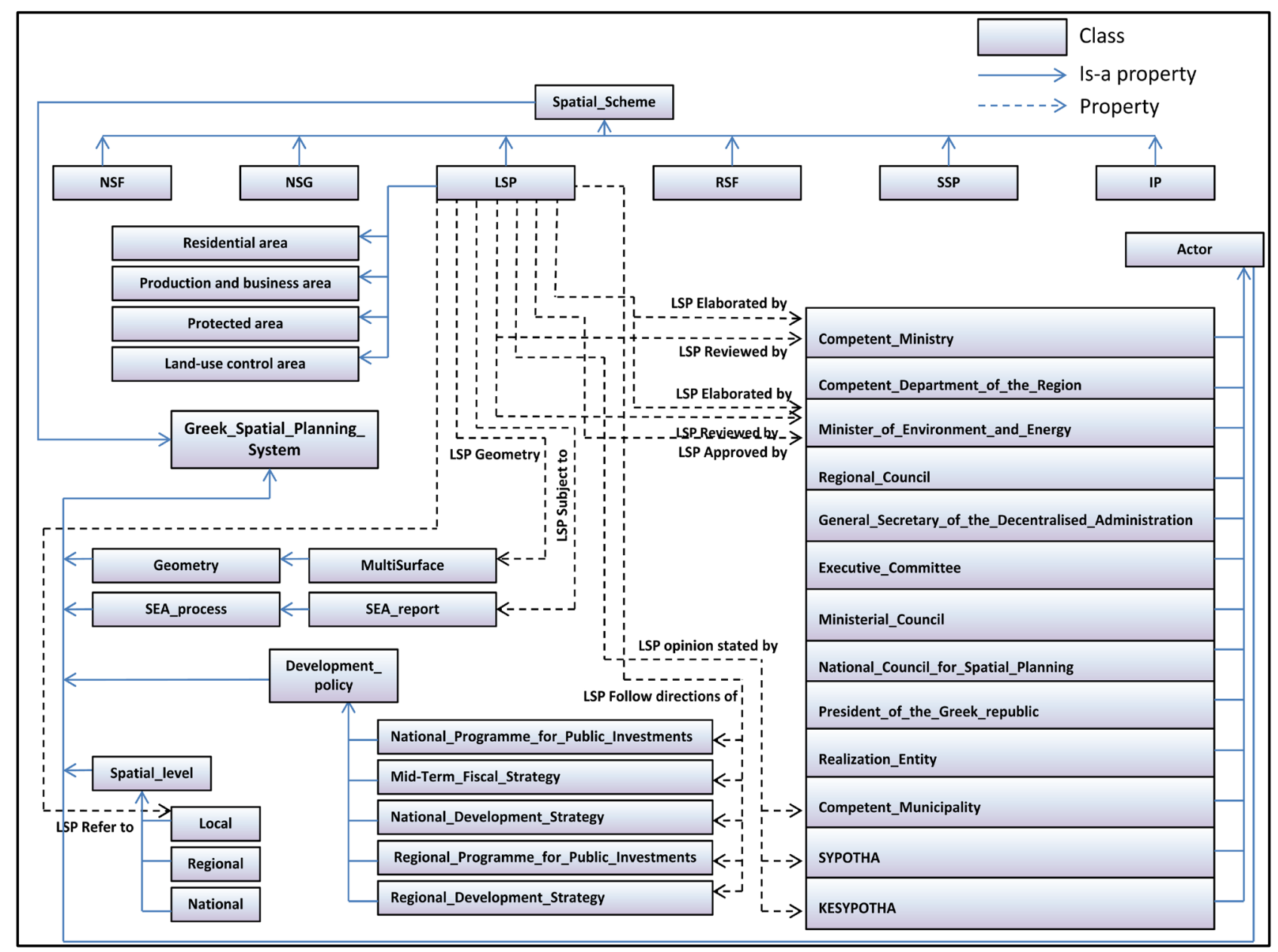

Figure 5. Classes and properties related to LSPs in proposed ontology. 
$\checkmark$ Areas of Specially Regulated Town-Planning (PERPOs), previewed in Article 24 of Law 2508/1997. These areas are located outside of the approved plans or settlements designated as legally existing before 1923 or at the boundaries of settlements housing fewer than 2000 residents. An urban study defines the terms and conditions and the building restrictions.

$\checkmark$ Areas of Urban Deterioration (POLEs), previewed in Article 31 of Law 4178/2013. POLEs are located in approved plans and settlements designated as legally existing before 1923 or at the boundaries of settlements housing fewer than 2000 residents. Within these areas, any urbanization must be directly connected to already urbanized areas of the municipality.

$\checkmark$ Building Rights Concentration Zones (ZSDDs), previewed in Article 24 of Law 4178/2013. These areas are spatial receptors or land exchange areas belonging to building cooperatives. ZSDDs can be located in the LSPs of mainland Greece, Crete, Rhodes, and the Euboea Islands, but are excluded from the administrative bounds of Athens, Thessaloniki, Ioannina, Patras, Volos, Larissa, and Iraklion. If located within an already existing LSP, a ZSDD is characterized as a spatial receptor and must adhere to a low building ratio. An urban study defines the terms, conditions, and building restrictions of a ZSDD.

2) Production and business areas

This category consists of within-plan or out-of-plan areas whose existing land-uses, existing infrastructure, and other spatial characteristics can facilitate production and business developments. The LSPs define the permitted categories of land-uses, building provisions, and restrictions for development within these areas.

3) Protected areas

These areas possess valuable natural and/or cultural characteristics requiring protection and promotion. Areas within this category, which are legally protected by specific regimes, include archaeological and historical sites, highly productive farming areas, forests, woodlands, and areas under the National System of Protected Areas (Law 3937/2011). Land uses, building provisions, and activities in these areas are restricted to protect the natural and/or cultural environment.

4) Land-use control areas

Land-use control areas are out-of-plan and out-of-settlement areas mainly located around residential areas or areas of production and business activities. Land uses and building provisions in these areas might be specifically restricted to achieve the rational and conflict-free distribution of land uses. Following the establishment of the LSPs, every residential, manufacturing, or other development initiative is permitted only when compatible with the existing constraints.

\subsubsection{Special Spatial Plans}

SSPs are established according to Law 4269/2014. In text and diagrams, the SSPs specify the required measures, conditions, and restrictions on land uses and building provisions, ensuring the appropriateness of strategically important large-scale programs or the management of land uses in areas needing specific restrictions. Hierarchically, SSPs occupy the same level as LSPs and must comply with the guidelines, priorities, and objectives of the NSG, NSFs, RSFs, and any other development policy over the wider region.

SSPs are proposed by the Ministry of Environment and Energy (based on the opinions of competent municipalities and SYPOTHAs). After approval, they are established through presidential decrees, which specify the guidelines, terms, and measures for environmental protection that should be followed under the SEA process. An SSP can be proposed by at least one of the following institutions: Ministry of Environment and Energy, a competent municipality, a competent region, or a realization entity. The Minister of Environment and Energy establishes the specifications for preparing an SSP. An SSP can amend any existing LSP or restrictions on land uses or building provisions, including the restrictions and provisions of any existing urban control zone. Although each LSP must follow the provisions of the relevant SSP, it can propose a modification to the SSP if the modification is supported by valid case-specific reasons and is approved by the institution that proposed the SSP. The Minister of Environment and Energy specifies the preparation, review, and amendment of SSPs. These relations are modeled in the proposed ontology (see Figure 6). However, no official geographically referenced database currently exists for established or under-review SSPs.

SSPs identify the following land-use categories:

$\checkmark$ Integrated Tourism Development Areas (POTAs), previewed in article 29 of Law 2545/1997. These areas consist of public or private land in approved LSPs and urban control zones or are established within already approved LSPs and urban control zones. POTAs are restricted to areas designated as appropriate for tourism 


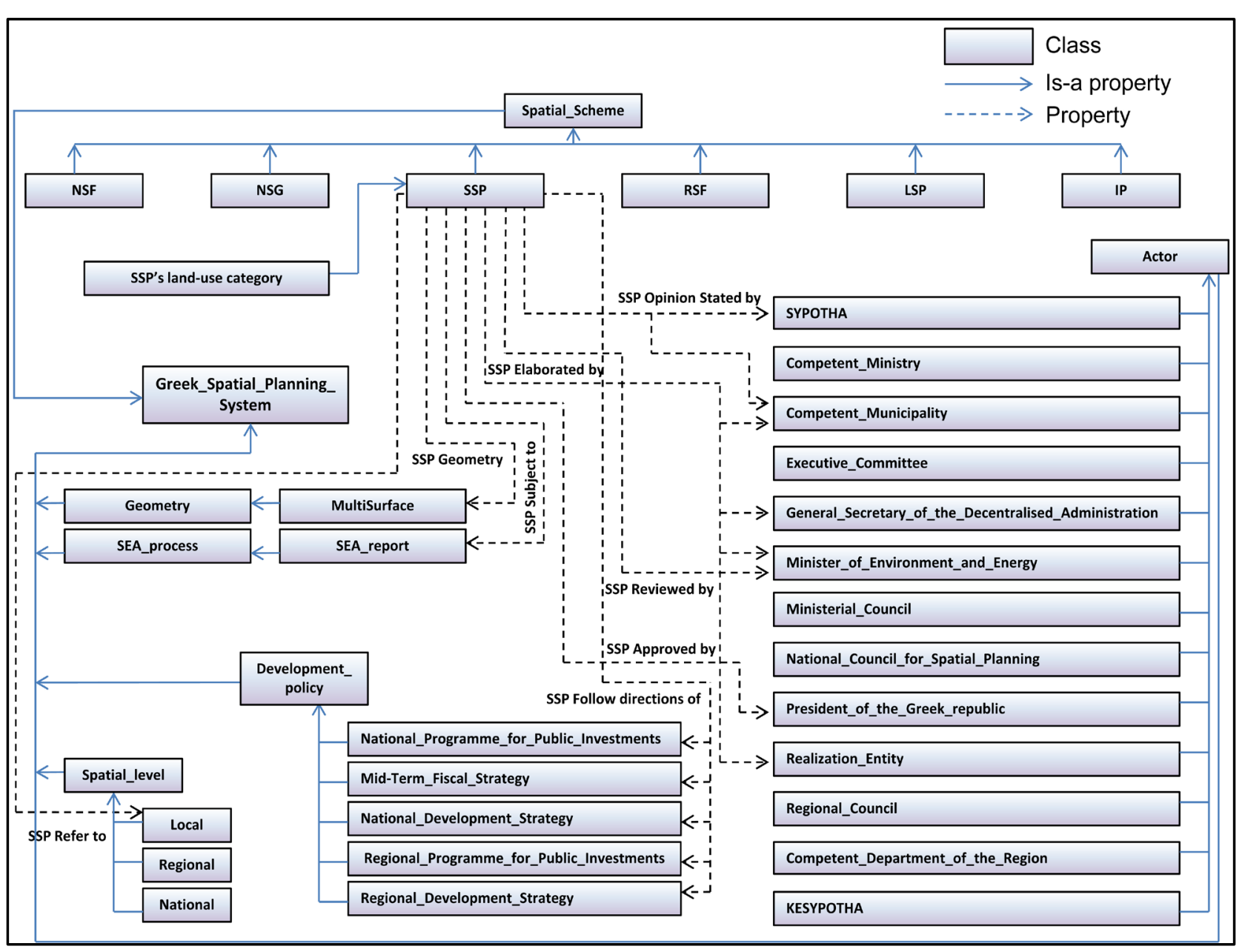

Figure 6. Classes and properties related to SSPs in proposed ontology.

development. An urban study defines the specific terms and building provisions of a POTA.

$\checkmark$ Areas for Organized Development of Tourism Productive Activities (POAPDs) previewed in Article 10 of Law 2742/1999. These areas are appropriate for production and business developments that are exclusively or primarily aimed at tourism. The designation accords with the directions approved in RSFs. The terms, conditions, and building restrictions in a POAPD are defined in an urban study.

$\checkmark$ Business parks, previewed in Article 41 of Law 3982/2011, are designated and urbanized following the provisions of Law 3982/2011. Business parks provide organized receptors for business activities that provoke any, high, medium, or low levels of disturbance (categorized as types A, B, C, and D, respectively).

$\checkmark$ Freight centers previewed in Article 1 of Law 3333/2005. These areas integrate the structures, services, and infrastructures of various types of transportation. Freight centers are erected and operated in areas that include or are connected to train stations, ports, or airports.

$\checkmark$ Special Plans for the Spatial Development of Public Real Estate (ESXADAs), previewed in Article 12 of Law 3986/2011, are located outside of the approved plans, in settlements designated as legally existing before 1923, or at the boundaries of settlements housing fewer than 2000 residents. They may also be located within new LSPs. An urban development study determines the permitted land uses and any additional restrictions.

$\checkmark$ Special Plans for the Spatial Development of Strategic Investments (ESXASEs), previewed in Article 24 of Law 3894/2010, are located in approved plans or settlements designated as legally existing before 1923 or at the boundaries of settlements housing fewer than 2000 residents. They may also be located within new LSPs.

$\checkmark$ Local plans previewed in Article 26 of Law 1337/1983, developed in approved plans or settlements desig- 
nated as legally existing before 1923 or at the boundaries of settlements housing fewer than 2000 residents. Local plans determine the appropriate areas for public and municipal buildings, buildings used for social purposes, and/or public housing buildings constructed for emergency purposes.

$\checkmark$ Areas of Environmental Upgrade and Private Urbanization (PPAIPs) previewed in Article 7 of Law 4280/2014. PPAIPs are located in approved plans or settlements designated as legally existing before 1923 or at the boundaries of settlements housing fewer than 2000 residents. The administrative bounds of Athens, Thessaloniki, Ioannina, Arta, Volos, Larissa, and Iraklion (in Crete) permit a subcategory of PPAIPs named Special Areas of Environmental Upgrade and Private Urbanization (SPPAIPs). EPPAIPs and PPAIPs have different approval requirements and urbanization provisions. To qualify as a PPAIP or an EPPAIP, an area must include a PERPO, according to Article 24 of Law 2508/1997. PPAIPs and EPPAIPs are regarded as SSPs and must be included in LSPs.

$\checkmark$ Special Projects for Environmental Upgrading and Development (ESPERAAs), previewed in Article 16 of Law 4280/2014, that aim to protect and revive abandoned, small, and dwindling settlements around the country. The competent municipalities must submit integrated promotion programs to the Ministry of Environment and Energy, which then assesses the settlements' characteristics, architecturally interesting buildings needing restoration, and public places needing protection and/or promotion. These programs must also comply with international conventions on the protection of landscapes and architectural and cultural heritage sites. ESPERAAs are regarded as SSPs and must be included in LSPs. An urban study defines the terms, conditions, and building restrictions of an ESPERAA.

For simplicity in Figure 6 these categories are presented as one class named "SSP's land-use categories" although actually in the proposed ontology each of them is designed as a different class.

\subsubsection{Implementation Plans}

Area urbanization requires the elaboration and approval of city-scale or sub-city-scale IPs. Since 2014 (Law 4269/2014), IPs have replaced the Town Plan Studies previewed in Law 2742/1999 and apply to areas or parts of areas to be urbanized by SSPs or LSPs. IPs impose restrictions on land uses and building provisions and detail the communal and building areas of cities as well as the infrastructure and networks necessary to urbanize such areas.

An IP is proposed by the relevant municipality or the Decentralized Administration after informing the competent municipality and is subjected to wide public consultation for at least 20 working days. The region's relevant department then consults the competent SYPOTHA and makes recommendations to the General Secretary of the Decentralised Administration, who makes the ultimate decision.

An Implementation Act (IA) is issued following the IP provisions. The Minister of Environment and Energy approves the specifications of both IPs and IAs and regulates the relevant details. An IP cannot be reviewed until five years after its establishment, unless specific needs necessitate its amendment. Since 2014 (Law 4269/2014), IPs have replaced the Town Plan Studies previewed in Law 2742/1999.

\subsection{Strategic Environmental Assessment Process and Public Consultation}

Public consultation in Greece is established through the EU Directive 2001/42. NSFs, RSFs, LSPs, and SSPs are subjected to the SEA process, and citizens can send their comments to competent authorities within 30 days before the plans are motivated. Moreover, the competent authorities can use electronic media, public hearings, interviews, open discussion, or online debates whenever necessary. The public consultation process examines the spatial planning objectives and procedures and the integrity of the SEA process. Moreover, public consultation is common to both the RSFs and their SEA processes. As described above, NSGs are not subjected to public consultation and are referred only to the National Council for Spatial Planning. Prior to the establishment of an IP, the relevant documents are announced to the municipality for 20 days (or 25 days for a substantiated recommendation) and are also published in the local press. During this time, citizens may appeal or request the modification of the documents. If an appeal is accepted, the documents are again announced to the municipality but no new appeals can be made.

\section{Conclusion and Future Research}

This paper develops an ontology that models the tradeoffs arising among the domestic actors, development poli- 
cies, spatial schemes, spatial schemes' administrative bounds and spatial levels of the spatial planning system as well as the evaluation process (which follows the SEA process) in a spatial planning system. Eight properties were designed to link the ontology's classes to the approval, elaboration, and review processes of each scheme. They are also related to the development policies applicable to each scheme, the spatial level to which the scheme is linked, the actors' official opinions of each scheme, the administrative bounds of each scheme and whether a particular scheme should follow the SEA process.

The ontology provides the core of a knowledge-based information system that can store, organize, retrieve and monitor the existing schemes and plans at the national, regional, and local scales. The ontology's applicability is demonstrated in modeling the Greek spatial planning system as such knowledge infrastructure is critically lacking in the Greek state. However, the ontology can be applied to model the trade-offs developed in various spatial planning systems, especially those that follow the urbanism planning tradition.

The paper's approach reveals that incorporating ontologies into spatial planning is a challenging research field that can create tools which facilitate the implementation of spatial planning policies because ontological approaches can deal with the complexity of spatial problems in terms of knowledge, cognition, perception, domestic actors' behaviours and expectations, roles and interactions. They are also becoming increasingly recognized as essential tools in information science because they can bridge the gaps between planners and stakeholders through digital information repositories.

In future research, structuring additional ontologies will be ventured so as to strengthen the incorporation of ontologies into spatial planning. To this end, the ontology will be linked to the infrastructure provided by the National Cadastre and Mapping Agencies. Moreover, an ontology-based Planning Support System that will offer a visualisation map Application Programming Interface (API) will be designed.

\section{Acknowledgements}

This research was generously supported by IKY Fellowships of Excellence for Postgraduate Studies in GreeceSiemens Program.

\section{References}

Agarwal, P. (2005). Ontological Considerations in GIScience. International Journal of Geographical Information Science, 19, 501-536. http://dx.doi.org/10.1080/13658810500032321

Arvor, D., Durieux, L., Andrés, S., \& Laporte, M. A. (2013). Advances in Geographic Object-Based Image Analysis with Ontologies: A Review of Main Contributions and Limitations from a Remote Sensing Perspective. ISPRS Journal of Photogrammetry and Remote Sensing, 82, 125-137. http://dx.doi.org/10.1016/j.isprsjprs.2013.05.003

Beard, K. (2012). A Semantic Web Based Gazetteer Model for VGI. Proceedings of the 1st ACM SIGSPATIAL International Workshop on Crowdsourced and Volunteered Geographic Information, Redondo Beach, 6-9 November 2012, 54-61. http://dx.doi.org/10.1145/2442952.2442962

Bellini, P., Nesi, P., \& Rauch, N. (2014). Knowledge Base Construction Process for Smart-City Services. 19th International Conference on Engineering of Complex Computer Systems (ICECCS), Tianjin, 4-7 August 2014, 186-189. http://dx.doi.org/10.1109/iceccs.2014.33

Berners-Lee, T., Hendler, J., \& Lassila, O. (2001). The Semantic Web. A New Form of Web Content That Is Meaningful to Computers Will Unleash a Revolution of New Possibilities. Scientific American, 284, 1-5.

Buccella, A., Cechich, A., \& Fillottrani, P. (2009). Ontology-Driven Geographic Information Integration: A Survey of Current Approaches. Computers \& Geosciences, 35, 710-723. http://dx.doi.org/10.1016/j.cageo.2008.02.033

Commission for Environmental Cooperation (CEC) (1997). The EU Compendium of Spatial Planning Systems and Policies Commission of the European Communities. Luxembourg, LU: EU Publications Office.

Directive, S.E.A. Directive 2001/42/EC of the European Parliament and of the Council of 27 June 2001 on the Assessment of the Effects of Certain Plans and Programmes on the Environment. Official Journal of the European Communities, L197, 30-37.

Dühr, S., Colomb, C., \& Nadin, V. (2010). European Spatial Planning and Territorial Cooperation. London: Routledge.

European Observation Network for Territorial Development and Cohesion (ESPON) (2015). Current Context of Integrated Territorial Development Strategic Planning in Greece. Engaging Greek Strategic Spatial Development. http://www.espon-interstrat.eu/admin/attachments/20110707181133_GREECE.pdf

Fenz, S. (2012). An Ontology-Based Approach for Constructing Bayesian Networks. Data \& Knowledge Engineering, 73, 
73-88. http://dx.doi.org/10.1016/j.datak.2011.12.001

Fonseca, F., Egenhofer, M., Davis, C., \& Borges, K. A. (2000). Ontologies and Knowledge Sharing in Urban GIS. Computers, Environment and Urban Systems, 24, 251-272. http://dx.doi.org/10.1016/S0198-9715(00)00004-1

Fox, M. S. (2015). The Role of Ontologies in Publishing and Analyzing City Indicators. Computers, Environment and Urban Systems, 54, 266-279. http://dx.doi.org/10.1016/j.compenvurbsys.2015.09.009

Garcia-Castro, R., Gómez-Pérez, A., \& Corcho, O. (2014). READY4SmartCities: ICT Roadmap and Data Interoperability for Energy Systems in Smart Cities. Proceedings of the 11th Extended Semantic Web Conference (ESWC'14), Anissaras, 25-29 May 2014. http://2014.eswc-conferences.org/sites/default/files/eswc2014euprojects_submission_28.pdf

Guyot, J., Falquet, G., \& Teller, J. (2010). Incremental Development of a Shared Urban Ontology: The Urbamet Experience. Formamente, 15, 132-139.

Harmonisation of Land-Use Data (HamonISA) (2015). http://harmonisa.uni-klu.ac.at/content/harmonisa-harmonisation-land-use-data

He, L., Yue, P., Jiang, L., \& Zhang, M. (2015). Fuzzy Spatial Relation Ontology Driven Detection of Complex Geospatial Features in a Web Service Environment. Earth Science Informatics, 8, 63-76. http://dx.doi.org/10.1007/s12145-014-0186-y

Hoehndorf, R. (2014). What Is an Upper-Level Ontology? http://ontogenesis.knowledgeblog.org/740

Jung, C. T., Sun, C. H., \& Yuan, M. (2013). An Ontology-Enabled Framework for a Geospatial Problem-Solving Environment. Computers, Environment and Urban Systems, 38, 45-57. http://dx.doi.org/10.1016/j.compenvurbsys.2012.10.008

Katranuschkov, P., Gehre, A., \& Scherer, R. J. (2003). An Ontology Framework to Access IFC Model Data. ITcon, 8, 413437.

Klien, E., Lutz, M., \& Kuhn, W. (2006). Ontology-Based Discovery of Geographic Information Services-An Application in Disaster Management. Computers, Environment and Urban Systems, 30, 102-123. http://dx.doi.org/10.1016/i.compenvurbsys.2005.04.002

Kohli, D., Sliuzas, R., Kerle, N., \& Stein, A. (2012). An Ontology of Slums for Image-Based Classification. Computers, Environment and Urban Systems, 36, 154-163. http://dx.doi.org/10.1016/j.compenvurbsys.2011.11.001

Komninos, N., Bratsas, C., Kakderi, C., \& Tsarchopoulos, P. (2015). Smart City Ontologies: Improving the Effectiveness of Smart City Applications. Journal of Smart Cities, 1, 31-46. http://dx.doi.org/10.18063/JSC.2015.01.001

Kyvelou, S. (2015). Brief Overview of Spatial Planning System in Greece. http://www.espon2013.panteion.gr/?q=el/esponhomeen\&page=1

Law 1337 (1983). Expansion of Urban Development Plans, Residential Development and Other Provisions. Greek Official Gazette (FEK) A, 1(33).

Law 2508 (1997). Sustainable Urban Development of the Cities and Settlements of the Country and Other Provisions. Greek Official Gazette (FEK) A, 1(124).

Law 2545 (1997). Industrial and Business Areas and Other Provisions. Greek Official Gazette (FEK) A, 1(254).

Law 2742 (1999). Spatial Planning and Sustainable Development. Greek Official Gazette (FEK) A, 1(207).

Law 3333 (2005). Establishment and Operation of Logistics Centres and Other Provisions. Greek Official Gazette (FEK) A, 1(238).

Law 3852 (2014). New Architecture of Local Government and Decentralized Administration—Kallikratis Programme. Greek Official Gazette (FEK) A, 1(87).

Law 3894 (2010). Acceleration and Transparency of Implementation of Strategic Investments. Greek Official Gazette (FEK) A, 1(204).

Law 3937 (2011). Biodiversity Conservation and Other Provisions. Greek Official Gazette (FEK) A, 1(60).

Law 3982 (2011). Fast-Track Licensing Procedure for Technical Professions, Manufacturing Activities and Business Parks and Other Provisions. Greek Official Gazette (FEK) A, 1(143).

Law 3986 (2011). Urgent Measures for the Application of Mid Term Fiscal Strategy Plan 2012-2015. Greek Official Gazette (FEK) A, 1(152).

Law 4178 (2013). Tackling Illegal Construction-Environmental Balance and Other Provisions. Greek Official Gazette (FEK) A, 1(174).

Law 4269 (2014). Spatial and Urban Reform—Sustainable Development. Greek Official Gazette (FEK) A, 1(142).

Law 4280 (2014). Environmental Upgrade and Private Urban Development-Sustainable Housing Development-Forest Law Regulations and Other Provisions. Greek Official Gazette (FEK) A, 1(159).

Legislative Decree of 17 July 1923 (1923). Planning and Building of the Cities, Towns, and Settlements of the State and 
Building. Greek Official Gazette (FEK) A, 1(228).

Li, W., Yang, C., \& Yang, C. (2010). An Active Crawler for Discovering Geospatial Web Services and Their Distribution Pattern-A Case Study of OGC Web Map Service. International Journal of Geographical Information Science, 24, 11271147. http://dx.doi.org/10.1080/13658810903514172

McGuinness, D. L., \& Van Harmelen, F. (2009). OWL Web Ontology Language Overview. https://www.w3.org/TR/2004/REC-owl-features-20040210/

Mejino Jr., J. L. V, Rubin, D. L., \& Brinkley, J. F. (2008). FMA-RadLex: An Application Ontology of Radiological Anatomy Derived from the Foundational Model of Anatomy Reference Ontology. Proceedings of the American Medical Informatics Association (AMIA) Annual Symposium, 465-469.

Montenegro, N., Gomes, J. C., Urbano, P., \& Duarte, J. P. (2012). A Land Use Planning Ontology: LBCS. Future Internet, 4, 65-82. http://dx.doi.org/10.3390/fi4010065

Nagy, E., Nagy, G., \& Timár, J. (2012). Transnational Comparison of National Policies and Planning Systems. Integrated Urban Development of Vital Historic Towns as Regional Centres in South East Europe.

http://www.southeast-europe.net/document.cmt?id=474

Noy, N. F., Crubezy, M., Fergerson, R. W., Knublauch, H., Tu, S. W., Vendetti, J., \& Musen, M. A. (2003). Protégé-2000: An Open-Source Ontology-Development and Knowledge-Acquisition Environment. Proceedings of the American Medical Informatics Association (AMIA) Annual Symposium, 953.

Otero-Cerdeira, L., Rodriguez-Martinez, F. J., \& Gómez-Rodriguez, A. (2014). Definition of an Ontology Matching Algorithm for Context Integration in Smart Cities. Sensors, 14, 23581-23619. http://dx.doi.org/10.3390/s141223581

Perry, M., \& Herring, J. (2012). GeoSPARQL_A Geographic Query Language for RDF Data. OGC Implementation Standard, 1-57. http://www.opengeospatial.org/standards/geosparql

Psyllidis, A., Bozzon, A., Bocconi, S., \& Titos Bolivar, C. (2015). Harnessing Heterogeneous Social Data to Explore, Monitor, and Visualize Urban Dynamics. Proceedings of the 14th International Conference on Computers in Urban Planning and Urban Management (CUPUM), 1-22.

Reynares, E., Caliusco, M. L., \& Galli, M. R. (2015). A Set of Ontology Design Patterns for Reengineering SBVR Statements into OWL/SWRL Ontologies. Expert Systems with Applications, 42, 2680-2690. http://dx.doi.org/10.1016/j.eswa.2014.11.012

SEMANCO (2015). The Semantic Tools for Carbon Reduction in Urban Planning. http://www.semanco-project.eu/

Serraos, K., Gianniris, E., \& Zifou, M. (2005). The Greek Spatial and Urban Planning System in the European Context. Complexity and Sustainability, Edizioni Polidesign, 2005, 1-24.

Stead, D., \& Cotella, G. (2011). Differential Europe: Domestic Actors and Their Role in Shaping Spatial Planning Systems. disP-The Planning Review, 47, 13-21. http://dx.doi.org/10.1080/02513625.2011.10557140

Teller, J., Billen, R., \& Cutting-Decelle, A. F. (2010). Bringing Urban Ontologies into Practice. Journal of Information Technology in Construction, 15, 108-110.

Visser, U., Stuckenschmidt, H., Schuster, G., \& Vögele, T. (2002). Ontologies for Geographic Information Processing. Computers \& Geosciences, 28, 103-117. http://dx.doi.org/10.1016/S0098-3004(01)00019-X

World Wide Web Consortium (W3C) (2012). OWL 2.0 Web Ontology Language Document Overview. http://travesia.mcu.es/portalnb/jspui/handle/10421/2425 


\section{Submit or recommend next manuscript to SCIRP and we will provide best service for you:}

Accepting pre-submission inquiries through Email, Facebook, Linkedin, Twitter, etc A wide selection of journals (inclusive of 9 subjects, more than 200 journals)

Providing a 24-hour high-quality service

User-friendly online submission system

Fair and swift peer-review system

Efficient typesetting and proofreading procedure

Display of the result of downloads and visits, as well as the number of cited articles

Maximum dissemination of your research work

Submit your manuscript at: http://papersubmission.scirp.org/ 